\title{
Transformación de la Estructura Urbana de la Ciudad de Toluca, Siglo XIX
}

Transformation of the Urban Structure of the city of Toluca, nineteenth Century

Dra. Georgina García Luna, Dr. Juan José Gutiérrez Chaparro

\section{Filiación}

Universidad Autónoma del Estado de México

Email: ginamasa@hotmail.com,urbania_jj@hotmail.com

Primera versión recibida en: 9 de julio de 2014

Última versión recibida en: 29 de diciembre de 2014

\section{Resumen}

La configuración urbana de las ciudades actuales, ha sido el resultado de distintos procesos históricos influyendo en la organización del territorio. Elementos como las actividades económicas y la aplicación de reformas urbanas, así como los equipamientos, servicios y los recursos humanos y físicos, han sido elementos que han intervenido en las áreas urbanas. El propósito del presente trabajo consiste en describir la transformación de la estructura urbana de la ciudad de Toluca a partir de la desamortización de bienes eclesiásticos, para identificar sus principales efectos en su traza urbana, en sus espacios públicos y en el crecimiento urbano de la ciudad. Con base en un fundamento historiográfico descriptivo, se logró demostrar que la desamortización ocasionó algunos cambios en la forma de la ciudad actual después de haberse vendido las propiedades del clero ya que hubo otros hechos que también impactaron en la configuración urbana de Toluca.

\section{Palabras Clave}

Estructura urbana; desamortización; propiedad

\begin{abstract}
The urban setting of today's cities, has been the result of different historical processes influencing the organization of the territory, elements such as economic activities and the implementation of urban reforms, as well as equipment, services and human and physical resources are elements who have spoken in urban areas. The aim of this paper is to understand the transformation of the urban structure of Toluca city - from the confiscation of church property - allowing us to identify the main effects in its urban layout, its public and urban growth of the city spaces. By using a historiographical approach, it was possible to demonstrate that the seizure caused some changes in the shape of the current city after church properties have been sold and there were other facts, which has also affected the urban configuration of Toluca.
\end{abstract}

\section{Keywords \\ Urban structure; confiscation; property}

\section{Sumario}

Introducción

1 Antecedentes

2 Legislación de la desamortización en México 1856-1862

3 Caso de estudio

4 Transformación de la estructura urbana de Toluca 1817-1877

Conclusiones 


\section{Bibliografía}

\section{Introducción}

En la actualidad existen estudios económicos y políticos que tratan el tema de la desamortización de los bienes de la Iglesia en México. Sin embargo, existe una carencia en investigaciones con relación a la estructura urbana de las ciudades en las que se llevó a cabo este proceso, considerando los efectos que provocó en sus propiedades, como uno de los indicadores significativos en el diseño y configuración urbana. Ello ha afectado de manera sustancial al mercado inmobiliario y en la expansión de la mancha urbana, siendo el origen en la formación de las áreas conurbadas y por lo tanto en las zonas metropolitanas actuales.

Al respecto, el área de estudio se refiere a la propiedad de los cuatro ex conventos de Toluca, México y la manera en que estos sufrieron transformaciones a causa de la desamortización de los bienes eclesiásticos efectuada en tres periodos distintos y por tres leyes distintas también: la de 1856, la de 1859 y la de 1862. Por lo tanto, el periodo de análisis corresponde de 1856 a 1862 y se examinan las propiedades urbanas y rurales que poseía cada una de las cuatro órdenes religiosas, las cuales se encontraron distribuidas dentro y fuera de la ciudad con el propósito de identificar el dominio y evolución territorial que presentó el clero una vez aplicada la desamortización, una de las aportaciones de este trabajo consiste en identificar los cambios que sufrió la estructura urbana de Toluca a partir de la venta de estos bienes, que se encontraban en manos muertas o sin producir.

Con lo anterior, la investigación tiene un fundamento historiográfico descriptivo. Se incluye el análisis conceptual, histórico y legal considerando que objeto de estudio es la propiedad conventual y la estructura urbana con un análisis evolutivo de planos históricos en distintas etapas: inicio, desarrollo y debilitamiento con respecto a los planos históricos de la Ciudad de Toluca de 1817, 1854 y 1877.

\section{Antecedentes}

La evolución de las ciudades se ha visto afectada por distintas fuerzas sociales, económicas y políticas, afectando la organización y diseño del territorio. La desamortización fue uno de los principales efectos en el territorio a causa de su relación tan directa en las propiedades. La aplicación de esta reforma contribuyó en gran parte en la estructura urbana de las ciudades, teniendo un impacto mayor en las ciudades evangelizadas, pues en ese sentido, la iglesia era una de las instituciones que poseía una ocupación importante del territorio, causando la desamortización de las propiedades eclesiásticas.

Al respecto, la propiedad de la Iglesia en nuestro país precisó la organización de las ciudades debido a sus grandes extensiones de tipo feudal por muchos años. Esta situación intervino en la conformación de la estructura urbana y, por lo tanto, en la definición de la traza urbana, la concentración de asentamientos humanos, de equipamiento administrativo, comercial y de servicios. De esta forma, se fueron desarrollando en su entorno las actividades más importantes.

En ese sentido y, con relación a nuestro tema de estudio, el concepto de desamortizar surge del término amortizar, refiriéndose a una propiedad inmueble que está en manos de una persona y que no puede ser vendida. Principalmente, los propietarios de estas tierras se encontraban en manos de la iglesia y de la monarquía, por lo tanto, no podían ser vendidas sus propiedades de manera que estancaba la producción del suelo (Martí, 2003:17).

En contraste, la desamortización consiste en vender los bienes nacionales o la apropiación de tierras por parte del estado, edificios pertenecientes a instituciones o entidades, facilitando la circulación del suelo en el mercado y el surgimiento de ciudades burguesas, ya que era la clase 
más beneficiada facilitar la venta y a un costo menor del valor de la propiedad generando mayor concentración de bienes (Rueda, 1997:10).

El término desamortización también se le conoce como "manos muertas", pues la propiedad no tenía ningún rendimiento, pues los propietarios de estas tierras no podían vender o por su extensión dificultaba su producción. Bassols (1973:66) señala que:

"la desamortización fue una de las reformas urbanas que tuvo incidencia en la estructura de la propiedad tanto urbana como rústica, la desaparición de limitaciones de orden feudal sobre el régimen jurídico de la propiedad; en la economía y lo social además de provocar la movilización de enormes extensiones territoriales que se transfieren al tráfico ordinario en beneficio de una nueva clase burguesa que constituirá el protagonista del movimiento de industrialización y de la urbanización".

Con las ideas anteriores, se identifica a la propiedad como el objeto principal de la desamortización, pues facilitó la circulación del suelo en el mercado afectando a la estructura de la ciudad y beneficiando a la clase burguesa, al convertirse en los principales compradores de los bienes a un costo menor de lo que valía realmente las tierras. Cuando las ciudades presentan conflictos de tipo económico y social surgen importantes razones para establecer e implementar políticas que permitan cambiar esta situación.

Al respecto, y en medio de diversos conflictos a lo largo de su historia, en el caso de México fueron distintas las razones que alentaron el proceso de desamortización desde la conquista española y hasta mediados del siglo XIX destacando al menos cinco momentos principales:

Primero, en México a mitad del siglo XVI, como resultado del dominio territorial a partir de la conquista espiritual, se dio un periodo de cristianización e hispanización de los indígenas, siendo la iglesia el principal instrumento que utilizaron los españoles para llevar a cabo dicho dominio y control sobre los grupos indígenas. Además de la Iglesia, surgió otra institución dominante en la sociedad colonial; la Hacienda, teniendo importancia en las ciudades de la Nueva España, debido a sus amplias superficies, pues en el caso de los conventos, funcionaban como ciudades al contar con sus propios servicios (Quiroz, 2008:38-39). Por ello, se destaca la gran riqueza de bienes que el clero conservó durante el siglo XVI y a mitad del siglo XIX. Otra razón que también originó la riqueza de la Iglesia en México, fue el no pago de impuestos, además de la vida austera de algunos clérigos y la donación de herencias, permitiendo mayor concentración en su riqueza (Bazant, 2011). Esta situación también se repetía en los mercaderes y prestamistas.

Segundo, mientras que la Iglesia se encontraba en una fase de riqueza, la situación del Estado era de pobreza, debido a que no fue buen administrador en sus bienes y tenía un excesivo gasto, lo que dificultaba la dotación de servicios en las ciudades, generando un rezago en el desarrollo del país (Bazant, 2011).

Tercero, después de la consumación de la independencia mexicana en 1821, la penuria fiscal, se planteó la posibilidad de una nacionalización de los bienes eclesiásticos. Pasaron treinta y cinco años de intermitente guerra civil hasta que la Ley Lerdo de 1856 con el gobierno de Gómez Farías acudió a la iglesia como fuente de recursos (Bazant, 1984:5). Al respecto, el Estado puso en venta los bienes de la iglesia pues era la institución que concentraba gran riqueza en el territorio. Esta situación también se presentó en España con el Primer Ministro Manuel Godoy en 1798, después de la guerra con Francia, implementando la primera desamortización del país la cual consistió en vender los bienes de cofradías, capellanías y hospitales (Barrios, 2009:23-24).

Cuarto, en México, a mediados del siglo XIX, los bienes inmuebles estaban bajo el control de propietarios que no les daban un uso productivo, lo que ocasionaba cuando menos en la 
administración del Estado, un vacío que imposibilitaba el desarrollo económico de la nación, situación que al inicio de la investigación señalamos como "manos muertas".

Finalmente, otra de las razones que alentaron la desamortización en México fue el estancamiento económico que vivía el país debido a distintos factores entre los que destaca el debilitamiento del sector agrícola provocado la contracción del mercado a causa de la guerra de Independencia. Otro factor fue la situación de la actividad minera que se encontraba casi arruinada por causa de las dificultades técnicas y el desorden general, dando como resultado a que las compañías extranjeras vendieran sus propiedades al capital mexicano (Bazant, 1977:6).

En efecto, se puede señalar que una de las razones principales que motivó a la desamortización de bienes de la Iglesia fue el estancamiento económico del estado y, considerando que la Iglesia era de las instituciones más favorecidas en la concentración de la riqueza, una de las alternativas que permitirían la solución de estos problemas, sería la adjudicación de los bienes de la iglesia. Ello, contribuiría al erario público al ponerlas en venta, considerando que muchas de sus propiedades no tenían ninguna productividad y no permitía la circulación de la riqueza. Sin embargo, no solo la economía fue la principal causa que motivó la desamortización, sino que también la desigualdad social fue otra de las causas que dio origen a desamortización.

Bajo este contexto, a continuación se señalan las leyes que abordaron el tema de desamortización entre 1856 a 1862.

\section{Legislación de la desamortización en México 1856-1862}

El proceso de desamortización en México se desarrolló en distintos procesos efectivos, el primero de 1856 a 1857, a través de la Ley Lerdo. Posteriormente, surge la del 13 de julio de 1859 y con la Ley del 5 de febrero de 1861, la que pretendió conciliar la Ley Lerdo. De estas tres leyes, la ley que tuvo mayores adjudicaciones fue la de 1861 , pues de 1856 a 1857 las propiedades que se vendieron fueron pocas (Bazant, 1979). Al respecto se hace una descripción de dichas leyes.

Ley Lerdo 25 de Junio 1856

De acuerdo al periodo de aplicación, la ley Lerdo fue el parteaguas de la desamortización y el principal antecedente que encadenó a las demás leyes desamortizadoras de la propiedad eclesiástica. La Ley Lerdo fue decretada por el Ministro de Hacienda del Presidente Comonfort, Miguel Lerdo de Tejada el 25 de Junio de 1856. De acuerdo con el artículo primero de esta ley, se señala lo siguiente: "todas las fincas rústicas y urbanas de las corporaciones civiles y eclesiásticas de la República, se adjudicarán en propiedad a los que las tienen arrendadas por el valor correspondiente a la renta que en la actualidad pagan, calculada como rédito al $6 \%$ anual." Se entiende por corporaciones de acuerdo con el artículo 3ro de la misma ley a todas las comunidades religiosas de ambos sexos, cofradías y archicofradías, hermandades, parroquias, ayuntamientos, colegios y, en general, todo establecimiento con carácter de duración perpetua o indefinida. La Ley afectaba tanto a la iglesia como a corporaciones públicas y privadas, civiles y religiosas (Bazant, 1979:45-46).

La finalidad de Miguel Lerdo fue circunscribir la influencia de la iglesia en los asuntos temporales. La Circular de 28 de junio del mismo año, que dirigió para acompañar a la ley, se fundaba en aspectos de mejoría económica, y comprendía 35 artículos que establecían la forma de adjudicación y remate de fincas, las excepciones, los denunciantes y la incapacidad para adquirir bienes raíces por parte de las corporaciones. Esta ley fue la causa indirecta del incremento del latifundismo de acuerdo con Porrúa (1995).

En seguida se señala el primer artículo de la Ley Lerdo del 25 de Junio de 1856, decretada por el gobierno, referida a la desamortización de fincas rústicas y urbanas que administren como 
propietarios las corporaciones civiles o eclesiásticas de la República (Dublan y Lozano, 1877, p. 197). Ignacio Comonfort, presidente sustituto de la República Mexicana, señala a los habitantes de la misma lo siguiente: "...uno de los mayores obstáculos para la prosperidad y engrandecimiento de la nación, es la falta de movimiento o libre circulación de una gran parte de la propiedad raíz, base fundamental de la riqueza pública; y en uso de las facultades que me concede el plan proclamado en Ayutla y reformado en Acapulco ha tenido a bien decretar lo siguiente...".

Art. 1 Todas las fincas rústicas y urbanas que hoy tienen o administran como propietarios las corporaciones civiles o eclesiásticas de la República, se adjudicaran en propiedad a los que las tienen arrendadas, por el valor correspondiente a la renta que en la actualidad pagan, calculada como rédito, al seis por ciento anual.

4. Una ley especial determinará la manera y forma de hacer ingresar al tesoro de la nación todos los bienes de que trata el artículo anterior.

5. Habrá perfecta independencia entre los negocios puramente eclesiásticos. El Gobierno se limitará a proteger con su autoridad el culto público de la religión católica, así como el de cualquiera otra.

6. Los ministros del culto, por la administración de los Sacramentos y demás funciones de su ministerio, podrán recibir las ofrendas que se les ministren, y acordar libremente con las personas que los ocupen, la indemnización que deban darles por el servicio que les pidan. $\mathrm{Ni}$ las ofrendas ni las indemnizaciones podrán hacerse en bienes raíces.

7. Se suprimen en toda la República las órdenes de los religiosos regulares que existen, cualquiera que sea la denominación ó advocación con que se hayan erigido, así como también todas las archicofradías, congregaciones o hermandades anexas a las comunidades religiosas, a las catedrales, parroquias o cualesquiera otras iglesias.

De acuerdo con lo anterior, el propósito de esta ley fue que la iglesia o el clero no intervinieran en asuntos políticos y que no tuviera un dominio y control territorial.

A diferencia de la Ley Lerdo, la ley de nacionalización de bienes eclesiásticos señala que entran al dominio de la nación todos los bienes del clero secular y regular, mientras que con la ley de 1856 las propiedades eclesiásticas podían ser compradas por los arrendatarios y también la ley del 12 de Julio de 1859 integró la prohibición de conventos regulares y el uso de hábitos. Por lo tanto, esta ley no solo trató asuntos de las propiedades o bienes del clero, sino que también comprendió dividir las actividades religiosas y políticas debido a la relación tan estrecha que existió entre el gobierno y la iglesia por muchos años.

Ley de nacionalización de bienes eclesiásticos del 12 de Julio de 1859

En 1859 se dio continuidad a la ley Lerdo a través de la Ley de nacionalización de bienes eclesiásticos del 12 de Julio de 1859, ley que también está considerada en el proceso de desamortización. Al respecto, se señala lo dispuesto en las propiedades eclesiásticas de dicha ley con el propósito de identificar si las similitudes o los cambios que se dieron entre las dos leyes (Dublan y Lozano, 1877, p. 215):

Art. 1 Entran al dominio de la nación todos los bienes que el clero secular y regular ha estado administrado con diversos títulos, sea cual fuere la clase de predios, derechos y acciones en que consistan, el nombre y aplicación que hayan tenido.

Ley del 5 de Febrero de 1861 
Una vez que se canceló la ley de nacionalización de bienes eclesiásticos del 12 de Julio de 1859, en 1861 se dio continuidad a la ley pero incorporando otras variables importantes (Dublan y Lozano, 1877, p. 265):

Art. 10. Toda venta, sea de fincas ó de cualquiera otra cosa, celebrada por el clero sin expresa autorización de las autoridades constitucionales, es nula y de ningún valor ni efecto.

Art.11. Los que poseyendo títulos de adjudicación, remate ó venta convencional anteriores al 17 de Diciembre de 1857, ó dados posteriormente por autoridades constitucionales, celebraron compras con el clero sobre las mismas fincas en que tienen dichos títulos, perdieron sus derechos de adjudicatarios, rematantes ó compradores convencionales, así como no adquirieron ninguno por contrato hecho con el clero, ni conservan derecho á devolución alguna, ni indemnización, sean cuales fueren las cantidades que hayan dado al clero, ó á cualquiera otra persona ó autoridad que no sea la constitucional. Si quisieran hoy recobrar los derechos primitivos de adjudicatarios, rematantes ó compradores, el gobierno les concede esta gracia, sin perjuicio de tercero, con la condición de que se aumente un 20p del capital que quedaba reconocido por la adjudicación, remate ó venta convencional, cuyo 20p seguirá para rendiciones ó reconocimiento, la misma suerte del capital primitivo. Los que quieran disfrutar de esta gracia, la manifestarán así dentro de treinta días contados desde la publicación de esta ley.

En ese sentido, se les regresará a los compradores las propiedades que ejercieron esta actividad de compra antes de 1857 o posteriormente sobre las fincas, en 1861. Sin embargo, esta ley no consideró la autonomía de la iglesia y del gobierno, por lo tanto, se puede deducir que con la ley de 1859 se aplicó este propósito por lo que ya no fue necesario incluirlo.

Una vez descritas las leyes de desamortización, se puede señalar que derivado del régimen de propiedad heredado desde la colonia, México padeció de un fuerte dominio territorial por parte de la Iglesia por más de 300 años, lo que provocó descontento de los liberales quienes, una vez que lograron el triunfo con los conservadores, impulsaron el proceso de desamortización a partir de la Ley Lerdo de 1856, la cual duro un año. Tres años más tarde, se da seguimiento con la ley de nacionalización de bienes eclesiásticos del 12 de julio de 1859 y con la ley del 5 de febrero de 1861. La ley de 1856 señala que una de las causas de la situación económica del país, era la falta de movimiento o libre circulación de una gran parte de la propiedad raíz, siendo base fundamental de la riqueza pública. En ese sentido, con la Ley Lerdo se pretendía la enajenación de propiedades civiles y eclesiásticas que estaban arrendadas por el valor correspondiente a la renta que en la actualidad pagan, calculada como rédito, al seis por ciento anual. Esta ley hacía referencia a las fincas urbanas y rurales que poseía el clero, sin embargo en 1857 se anula la ley.

A través de la ley de nacionalización de bienes eclesiásticos del 12 de julio de 1859, se da continuidad a ley Lerdo de 1856. Con la ley de 1859 se pretendió que se les devolvieran los títulos de adjudicación a los compradores de las propiedades que fueron adquiridas con base en la ley Lerdo de 1856. Por lo tanto, entran al dominio de la nación todos los bienes que el clero secular y regular había administrado con diversos títulos, además de que se dará una separación entre los negocios eclesiásticos y el Gobierno. De esta forma, se disminuyen los privilegios que el clero tenia por medio de sus propiedades.

Por su parte, mediante la ley del 5 de febrero de 1861 quedan legitimadas las propiedades adquiridas antes de 1857, ya que sus compradores habían perdido sus derechos de adjudicatarios, rematantes o compradores convencionales después de 1857 y como no habían adquirido ningún contrato ante el clero, ni habían conservado derecho a devolución alguna, ni indemnización, sean cuales fueren las cantidades que hayan dado al clero, ó a cualquiera otra 
persona ó autoridad que no sea la constitucional, mediante esta Ley se les otorgó legitimidad a la compra de las propiedades.

En este contexto, el proceso de desamortización en México duró entre 1856 a 1961, periodo en el que fueron interrumpidas las leyes y que después volvieron a retomarse, de manera que la propiedad del clero en este periodo comenzó a debilitarse y a disminuir su poder y control en el territorio. Al respecto a continuación se señala la aplicación de la desamortización en los bienes eclesiásticos en México.

Con lo anterior, con las leyes del 25 de Junio 1856, la del 12 de Julio de 1859 y la del 5 de Febrero de 1861, el valor de las propiedades durante el proceso de desamortización en estos tres periodos fue mayor a la que registraron los estudios hechos por Florescano y Milada Bazant, considerando que sus estudios se realizaron únicamente en 1856 y que las propiedades fueron regresadas a sus dueños originales en 1857; en 1857 y 1861 se dio continuidad a la ley de 1856 devolviendo las propiedades que habían sido adjudicadas además de promulgarse que las propiedades conventuales debían de desaparecer.

\section{Caso de estudio}

En el siguiente apartado se muestra un diagnóstico del estado original de las propiedades del convento franciscano, vale decir, de la Merced, del Carmen y de San Juan de Dios, pertenecientes a la ciudad de Toluca. El propósito de identificar si dichas propiedades sufrieron alguna transformación y el impacto en la estructura urbana de la ciudad de Toluca. Cabe aclarar que las órdenes religiosas son instituciones conventuales o sociedades religiosas, cuyos miembros están ligados por los votos solemnes de pobreza, castidad, obediencia y viven en comunidad y el convento se refiere a su lugar de residencia.

\begin{tabular}{|l|r|r|r|r|}
\hline \multicolumn{1}{|c|}{ Convento } & \multicolumn{1}{|c|}{$\begin{array}{c}\text { Total de } \\
\text { propiedade } \\
\text { s en pesos }\end{array}$} & $\begin{array}{c}\text { Fincas } \\
\text { urbanas } \\
\text { en pesos }\end{array}$ & $\begin{array}{c}\text { Fincas } \\
\text { rústicas } \\
\text { en pesos }\end{array}$ & $\begin{array}{c}\text { Total de fincas } \\
\text { urbanas y } \\
\text { rurales en } \\
\text { pesos }\end{array}$ \\
\hline $\begin{array}{l}\text { Convento } \\
\text { Franciscano }\end{array}$ & 66,484 & 51,384 & 8,400 & 59,784 \\
\hline $\begin{array}{l}\text { Convento del } \\
\text { Carmen }\end{array}$ & 141,324 & 114,811 & 17,200 & 132,011 \\
\hline $\begin{array}{l}\text { Convento de la } \\
\text { Merced }\end{array}$ & 7,565 & 4,485 & 1,320 & 5,805 \\
\hline $\begin{array}{l}\text { Convento de San } \\
\text { Juan de Dios }\end{array}$ & 2,850 & 2,850 & 0 & 2,850 \\
\hline Total & $\mathbf{2 1 8 , 2 2 3}$ & $\mathbf{1 7 3 , 5 3 0}$ & $\mathbf{2 6 , 9 2 0}$ & $\mathbf{2 0 0 , 4 5 0}$ \\
\hline
\end{tabular}

Tabla 1 Total de capital de fincas urbanas y rústicas conventuales de 1785 a 1863

Fte: Elaboración propia con base en censo de 1860

Los datos de la Tabla 1 se refieren al valor de las propiedades urbanas y rusticas. El Convento del Carmen fue el clero más rico concentrando un total de 141,324 pesos en propiedad, seguido de los franciscanos con 66,484; mientras que el convento de la Merced y de San Juan de Dios concentraban poco valor en sus propiedades (ver Fig. 1). 


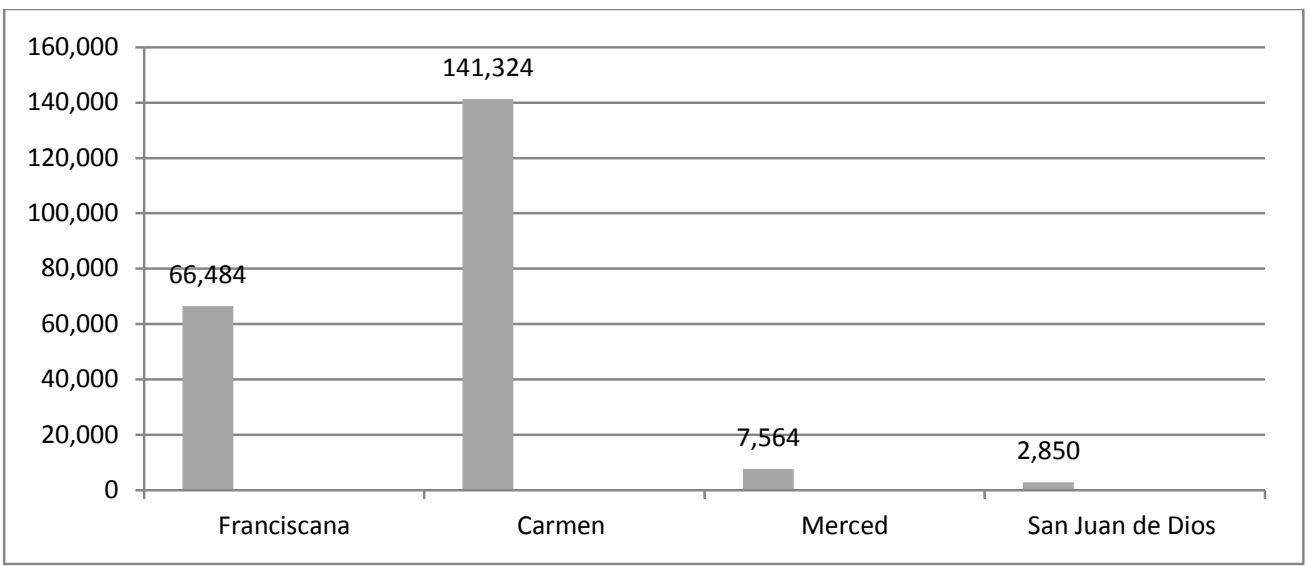

Fig. 1 Total del valor de las propiedades de las órdenes religiosas, 1785-1863 Fuente: Elaboración propia con base en censo de 1860

De acuerdo con la Fig. 1, se incluyeron caballerías, ladrilleras, solares, varios, propiedades en negociación, propiedades de media tierra, solares, por lo que no solo se refiere a casas y haciendas o ranchos. A continuación se presenta un gráfico en el que solo se incluyen fincas urbanas es decir casas dentro de la ciudad (ver Fig. 2).

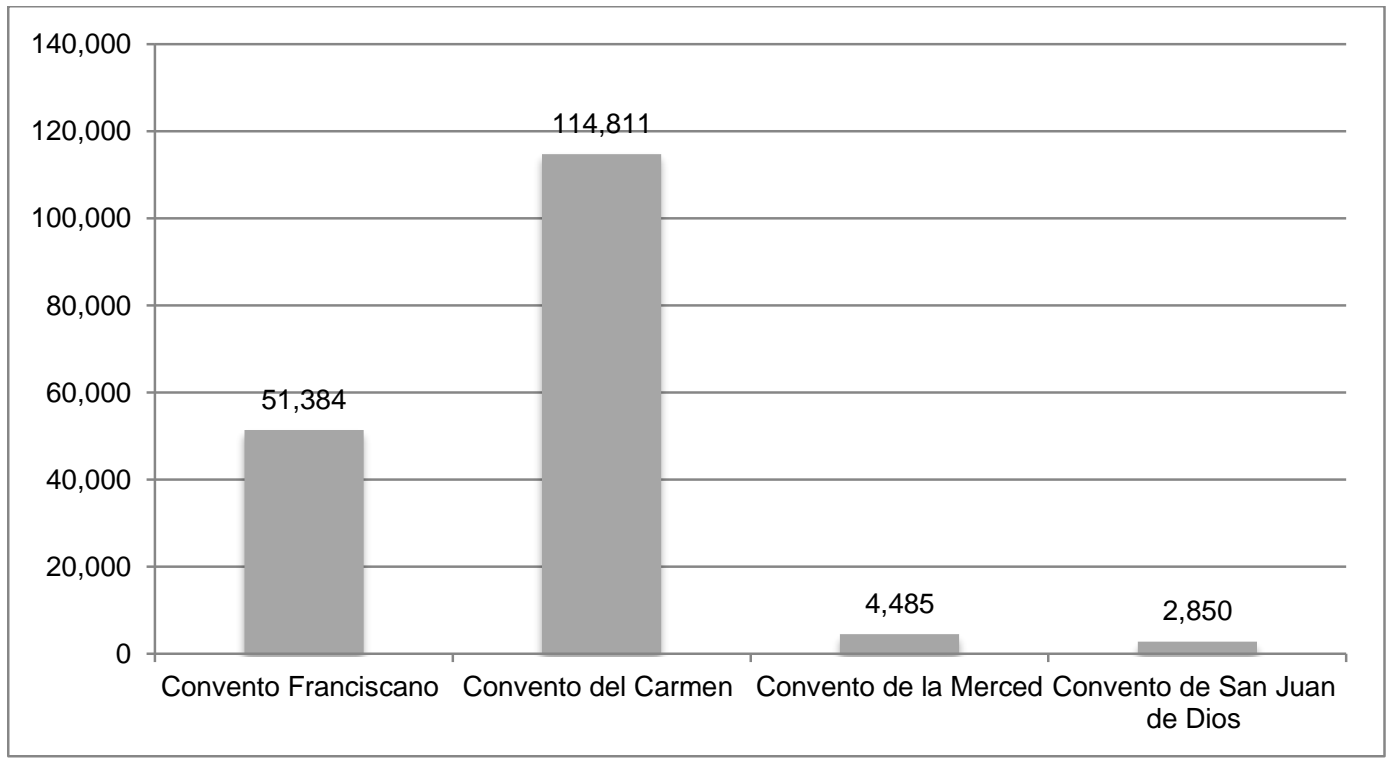

Fig. 2 Capital de las fincas urbanas conventuales, 1785-1865

Fuente: Elaboración propia con base en censo de 1860

En este nuevo gráfico, se puede ver que las propiedades del Convento del Carmen son las de mayor valor respecto a las otras órdenes aun cuando el Convento Franciscano tenía mayor cantidad de propiedades, sin embargo su valor era menor. En cuanto a la ubicación de sus propiedades urbanas, ésta se dio de manera dispersa. al respecto, y considerando la localización señalada por las actas de los archivos notariales y con base en el plano de 1817 y de Solalinde de 1877, también se consideró el valor de las propiedades en rangos los cuales fueron representados de la siguiente manera, ver Fig. 3. 


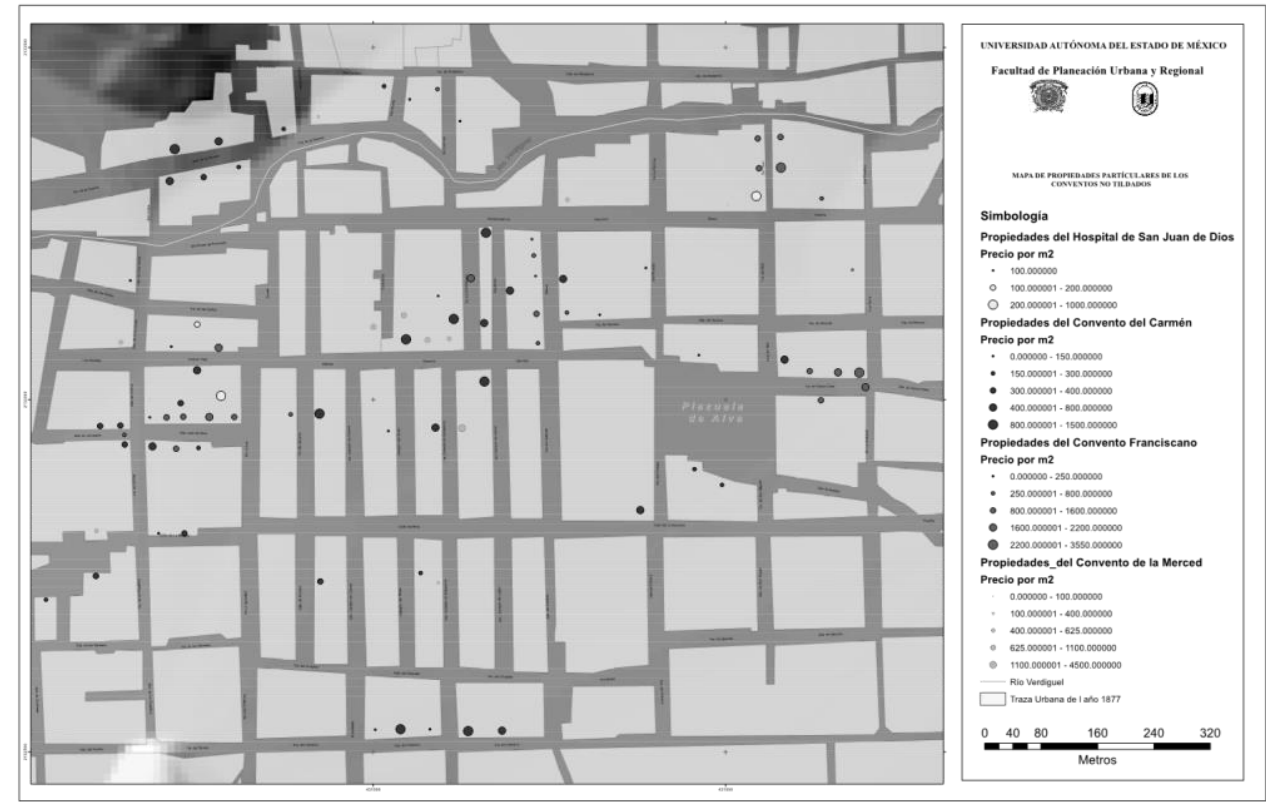

Fig. 3 Ubicación de propiedades conventuales en la Ciudad de Toluca, 1785-1865

Fuente: elaboración propia con base en censo de 1860 y plano de Domínguez de Mendoza (1817)

En la Fig. 3, se distinguen a la orden de los franciscanos como los principales propietarios conventuales registrando 42 propiedades, mostrando una concentración mayor de propiedades en la $2^{a}$ Calle de la Tenería (hoy Lerdo), así como en la Calle de San Juan de Dios (Hoy Plutarco González) y en la $2^{a}$ y $1^{a}$ Calle del Calvario (hoy Valentín Gómez Farías), localizada casi en la periferia de la ciudad. Los carmelitas descalzos también presentan una importante agrupación de propiedades con un total de 34, ubicadas en su mayoría en calle de las Flores (hoy Juárez), en la calle de San Juan de Dios (hoy Plutarco González) a un costado del Convento San Juan de Dios, y en la Calle $1^{\text {a }}$ de Santa Clara (hoy Hidalgo).

El Convento de la Merced poseía tan solo 10 propiedades localizadas de manera dispersa, sin embargo presentaba una pequeña concentración de 4 propiedades sobre la calle Libertad, en el primer cuadro del corazón de la ciudad de Toluca. Mientras que el Convento de San Juan de Dios poseía solo cuatro propiedades localizadas de manera muy dispersa en la ciudad.

A pesar de que los Franciscanos poseían mayor cantidad de propiedades en la ciudad, su valor total era menor al valor total de las propiedades de los carmelitas descalzas. Esto se podría explicar porque su extensión era mayor al de las propiedades franciscanas. El valor total de las propiedades de los carmelitas superaban un poco más del $50 \%$ al de los franciscanos. En cuanto al valor total de las propiedades de los mercedarios y de los juaninos, concentraban un valor mucho menor al comparado con los Carmelitas y Franciscanos.

También es importante destacar que las propiedades de las casas de los conventos se localizaban en torno a los conventos, con excepción del Convento de la Merced, así como cerca del Río de la Tenería (hoy calle Lerdo) y en calles principales del centro de la ciudad. Otro de los aspectos importantes es la ubicación de propiedades de los franciscanos en la periferia de la ciudad, siendo el caso de la Calle Serratana (hoy calle Humboldt) al oriente de la ciudad, en la $1^{a}$ y $2^{a}$ del Calvario en el norte de la ciudad, en la $2^{a}$ de Jerusalén (hoy Plutarco González) al poniente y al norte en la calle de la Tenería (hoy Lerdo), siendo sitios estratégicos durante la evangelización. 
A continuación se señala las fincas que tenían los conventos fuera de la ciudad de Toluca desde 1785 hasta 1857.

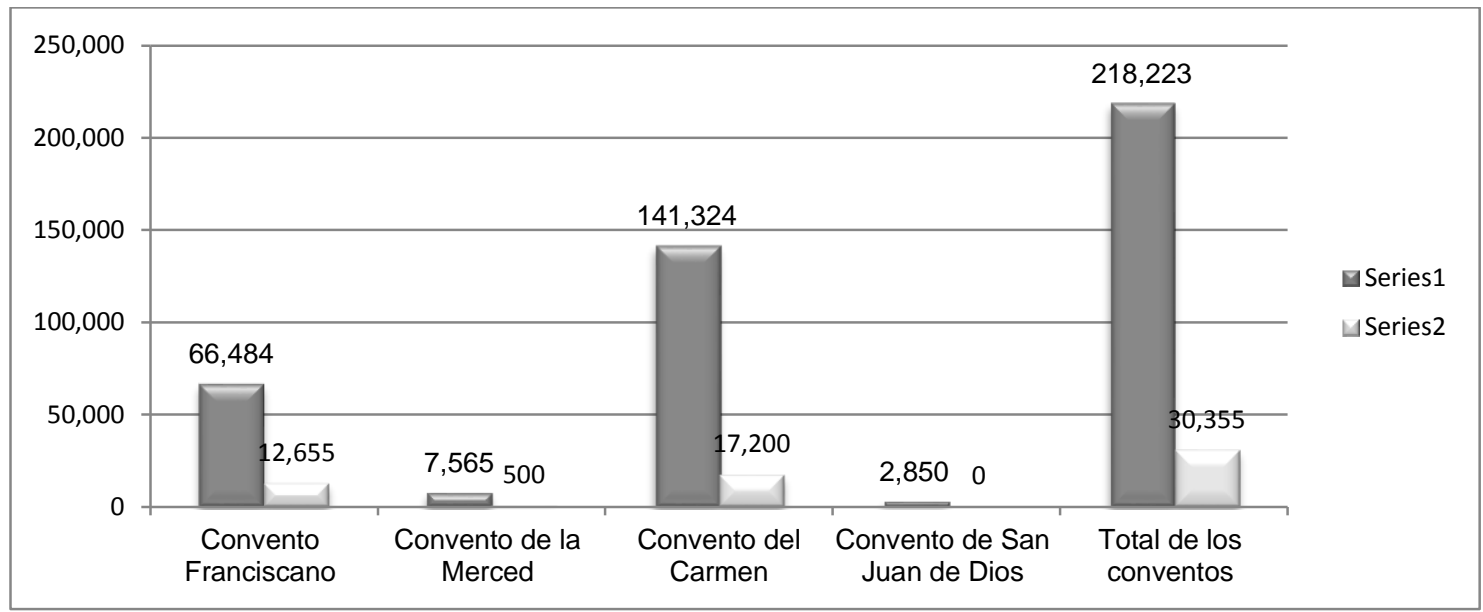

Fig. 4 Valor de las propiedades de los conventos, en Toluca de 1785-1865 y 1861-1865 Fuente: Censo de $1860^{1}$ y Censo 1865

La gráfica anterior (Fig. 4) muestra claramente que la aplicación de la desamortización de bienes eclesiásticos cumplió su objetivo en el caso de la ciudad de Toluca, ya que se observa una reducción importante en el valor de la riqueza que tenía el clero entre 1861 a 1865 en propiedad. Por lo tanto, la ciudad dejo de tener grandes lotes y pasó a ser una ciudad burguesa albergando a políticos del gobierno, así como extranjeros y comerciantes siendo los principales compradores de las propiedades vendidas por el clero y por lo tanto pasaron a ser los primeros precursores del mercado inmobiliario en la ciudad de Toluca.

\section{Propiedades conventuales convertidas en Iglesias en 1899}

Para 1899 las propiedades conventuales, dejaron de existir y pasaron a ser iglesias de acuerdo con el censo de $1899^{2}$ en el expediente del catálogo especial del archivo municipal de Toluca, solicitado por el $\mathrm{H}$. Ayuntamiento de Toluca al clero en 1899. Estos catálogos indican el estado de la propiedad que poseían en 1899 el clero, su ubicación, colindancias, superficie, dependencias y el valor de la propiedad. A continuación se presenta un cuadro comparativo de las propiedades que conservaron los conventos analizados (ver Tabla 2). 


\begin{tabular}{|c|c|c|c|c|c|c|c|}
\hline $\begin{array}{c}\text { Ex } \\
\text { Convento }\end{array}$ & Nombre & Ubicación & Medidas & Colindancias & Valor & $\begin{array}{c}\text { Valor de } \\
\text { m2 }\end{array}$ & Área m2 \\
\hline Franciscano & \begin{tabular}{|l} 
Iglesia \\
Parroquial de \\
Toluca
\end{tabular} & $\begin{array}{l}\text { En la cabecera } \\
\text { de la catedral en } \\
\text { construcción, } \\
\text { dedicada a San } \\
\text { Francisco }\end{array}$ & $\begin{array}{l}\text { Mide de longitud } 39 \\
\text { mts. De latitud } 9 \mathrm{~m} \text { y } \\
\text { el crucero } 19 \mathrm{~m} \text {; una } \\
\text { capilla que mide de } \\
\text { longitud } 16 \mathrm{~m} \text { y de } \\
\text { latitud } 6 \mathrm{~m} \text {. un } \\
\text { bautisterio, dos } \\
\text { sacristías y un patio: } \\
\text { una habitación para } \\
\text { párroco que tiene } \\
\text { cinco piezas y un } \\
\text { pasillo para la entrada } \\
\text { al curato; hay un atrio } \\
\text { de la capilla que mide } \\
24 \mathrm{~m} .30 \mathrm{c} \text {. }\end{array}$ & $\begin{array}{l}\text { Por el oriente con casa } \\
\text { del Sr. Alberto Henkel } \\
\text { : por el sur con casa } \\
\text { rojas: por el poniente } \\
\text { con la casa del sr. } \\
\text { Carlos Moreno y por el } \\
\text { Norte con la catedral } \\
\text { en construcción. }\end{array}$ & $\begin{array}{l}19,000 \\
\text { pesos }\end{array}$ & $\begin{array}{l}\text { No hay } \\
\text { dato } \\
\text { exácto }\end{array}$ & $\begin{array}{l}\text { No hay } \\
\text { dato } \\
\text { exácto }\end{array}$ \\
\hline La Merced & $\begin{array}{l}\text { Iglesia de la } \\
\text { Merced }\end{array}$ & $\begin{array}{l}\text { En el Barrio de } \\
\text { la Merced hoy } \\
\text { Calle Morelos }\end{array}$ & $\begin{array}{l}\text { La extensión general } \\
\text { de la superficie del } \\
\text { terreno es } 2,326 \\
\text { metros cuadrados. En } \\
\text { este está construido el } \\
\text { templo y mide } 890 \\
\text { m2 }\end{array}$ & $\begin{array}{l}\text { El espacio que ocupa } \\
\text { sus linderos son: por } \\
\text { el oriente con la casa } \\
\text { de la Señora Emilia } \\
\text { López: por el poniente } \\
\text { con la casa } \\
\text { correccional, por el sur } \\
\text { con la calle de Merced } \\
\text { y por el norte con el } \\
\text { terreno de Don } \\
\text { Anselmo Bernal }\end{array}$ & $\begin{array}{c}\text { de } 50,000 \\
\text { a } 60,000 \\
\text { pesos, }\end{array}$ & 23.64 & $\begin{array}{l}2,326 \\
\text { m2 }\end{array}$ \\
\hline $\begin{array}{l}\text { Hospital de } \\
\text { Nuestra } \\
\text { Señora de } \\
\text { Guadalupe y } \\
\text { del Señor } \\
\text { San José }\end{array}$ & $\begin{array}{l}\text { Iglesia de } \\
\text { Guadalupe }\end{array}$ & $\begin{array}{l}\text { Ubicado en la } \\
\text { esquina de la } \\
\text { calle de la Ley } \\
\text { (actualmente } \\
\text { Villada) y } \\
\text { Callejón de San } \\
\text { Juan de Dios, }\end{array}$ & $\begin{array}{l}\text { La extensión } \\
\text { superficial del Templo, } \\
\text { inclusive la sacristía y } \\
\text { un pequeño atrio es } \\
\text { de } 453 \text { metros } 54 \\
\text { centimetros. }\end{array}$ & $\begin{array}{l}\text { Linda por el norte con } \\
\text { el callejón de San Juan } \\
\text { de Dios, por el Sur con } \\
\text { el Palacio de Justicia, } \\
\text { al Oriente con la calle } \\
\text { de la ley y al poniente } \\
\text { con la casa de } \\
\text { Sóstenes Vilchis. }\end{array}$ & $\begin{array}{l}8,000 \\
\text { pesos }\end{array}$ & 0.056 & $\begin{array}{c}453.54 \\
\mathrm{~m} 2\end{array}$ \\
\hline Carmen & $\begin{array}{l}\text { Iglesia del } \\
\text { Carmen }\end{array}$ & & $\begin{array}{l}\text { La extensión } \\
\text { superficial del Templo, } \\
\text { sacristía, pazadiso y } \\
\text { atrio es } \\
\text { aproximadamente } \\
\text { según se ha } \\
\text { informado la de } \\
3000 \mathrm{~m} 2\end{array}$ & $\begin{array}{l}\text { Por el norte huerta del } \\
\text { Sr. Francisco Pichardo } \\
\text { y casa del Sr. Benitez; } \\
\text { por el sur calle del } \\
\text { Carmen por el oriente } \\
\text { Plazuela del mismo } \\
\text { nombre y por el } \\
\text { poniente con la } \\
\text { escuela Normal para } \\
\text { Señoritas. }\end{array}$ & 120,000 & 40 & $3000 \mathrm{~m} 2$ \\
\hline
\end{tabular}

Tabla 2 Propiedades Conventuales convertidas en Iglesias en 1899 Fuente: Elaboración propia con base en Censo de 1899

De acuerdo con el cuadro anterior, en 1899 las colindancias de los cuatro ex conventos eran las siguientes: la propiedad del convento franciscano en su mayoría quedó en manos de algunos particulares mientras que los demás conventos siguieron conservando sus capillas principales con acceso a calles principales de la ciudad siendo el caso de la Merced en Av. Morelos, la Iglesia de Sta. Ma. de Guadalupe en la calle de Vicente Villada y la Iglesia del Carmen sobre la calle de Santos Degollado. Gran parte de las propiedades de los cuatros conventos fueron reemplazados por edificios públicos por ejemplo al norte del convento franciscano se localizó la Catedral, al poniente del convento del Carmen se ubicó la Escuela Normal para Señoritas, al sur del convento de San Juan se ubicó el Palacio de Justicia y al poniente de la Merced la casa Correccional en 1899. 
En cuanto a las propiedades de los conventos del Carmen, Franciscano y de la Merced fueron los que concentraban mayores extensiones de propiedad a diferencia del Convento y Hospital de San Juan de Dios, sin embargo sufrieron una disminución importante en sus propiedades tomando en cuenta la propiedad original de dichos conventos, ver Fig. 5.

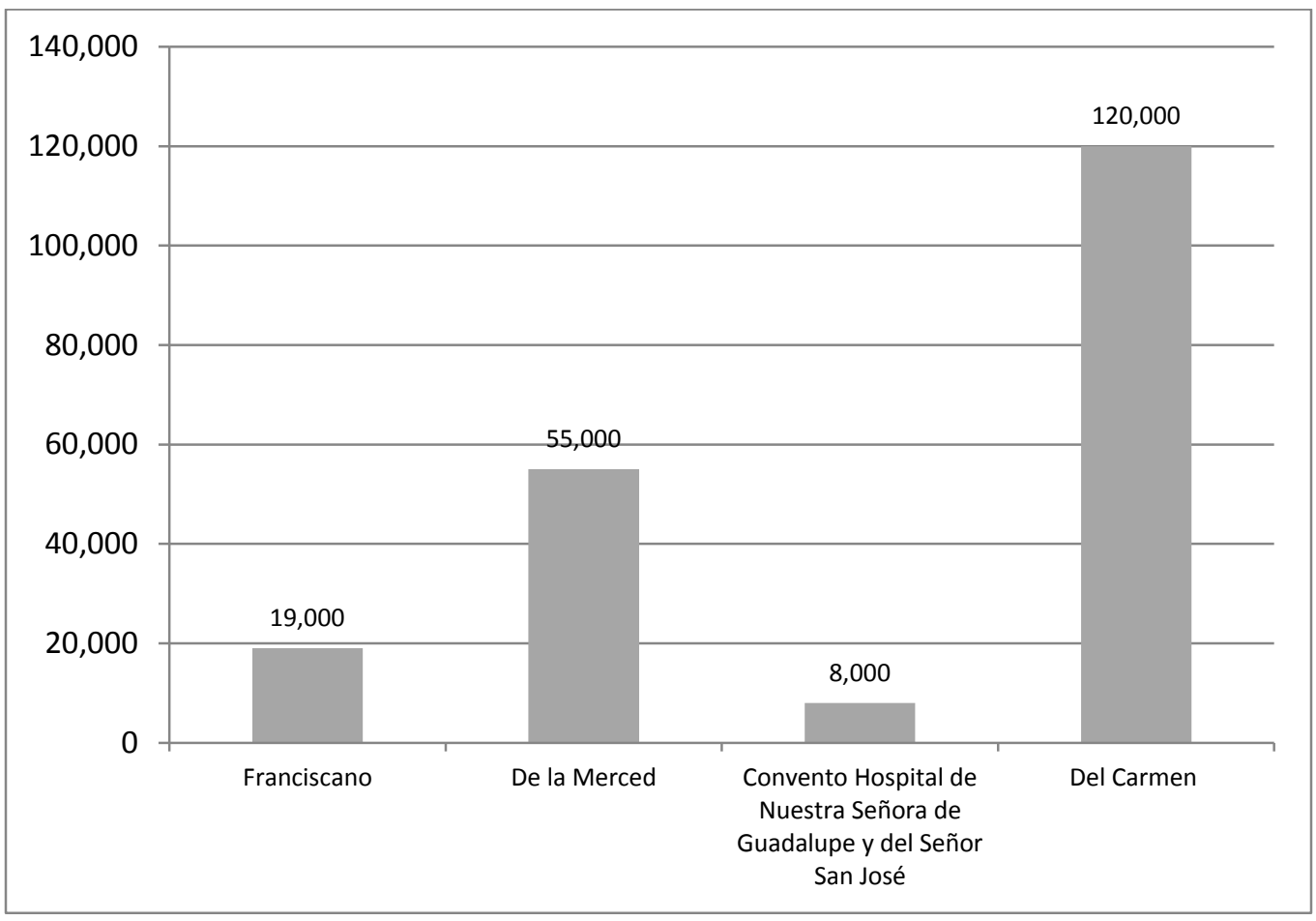

Fig. 5 Valor de las propiedades de los ex conventos en 1899 Fuente: Censo de 1899

El valor de la propiedad tiene una relación directa con el total de la superficie. Sin embargo, se puede observar que la extensión de la propiedad de la Iglesia de la Merced correspondiente a 2,326 m2, tiene una diferencia de $674 \mathrm{~m} 2$, comparado con la propiedad de la Iglesia del Carmen que si bien es menor en extensión, según se observa en el gráfico su valor es significativamente mayor; esta situación hace suponer que el valor del suelo al norte de la ciudad de Toluca era mayor al de la zona poniente donde se ubica la Merced, quizás por situarse más cerca del centro de la ciudad, tal y como sucede con la propiedad de la Iglesia de Sta. Ma. De Guadalupe que a pesar de abarcar menor extensión en su propiedad, se ubica en el corazón de la ciudad.

De acuerdo con lo anterior, Toluca presentó cambios significativos en su estructura urbana antes de la desamortización eclesiástica, siendo el caso en 1830, cuando Toluca se declaró como capital del Estado de México, lo que dio paso a una mejoría en las calles principales del primer cuadro de la ciudad,. Asimismo se comenzó con la construcción de los portales Constitución dentro del polígono del Convento Franciscano en 1832 parte de la huerta y del cementerio en la zona poniente con 37 arcos. Más tarde en 1850, se dio continuidad a los portales en la zona poniente del convento siendo el cementerio y que hoy en día es el portal Reforma con 35 arcos, por lo tanto se presentaron cambios significativos en las propiedades conventuales en el transcurso de 60 años.

Además de las transformaciones sufridas en la propiedad del Convento Franciscano, también se presentó en el Convento de los Carmelitas Descalzos después de la mitad del siglo XIX al igual 
que el I Convento de la Merced localizado al poniente de la ciudad. A diferencia de estos tres conventos, el Hospital de Nuestra Señora Guadalupe y del Señor San José hoy Iglesia de Sta. Ma. Guadalupe ubicado en la calle de San Juan de Dios (plano 1817) hoy Vicente Villada tenía menos propiedad sin embargo también contenía un camposanto al igual que los demás conventos (ver Fig. 6).

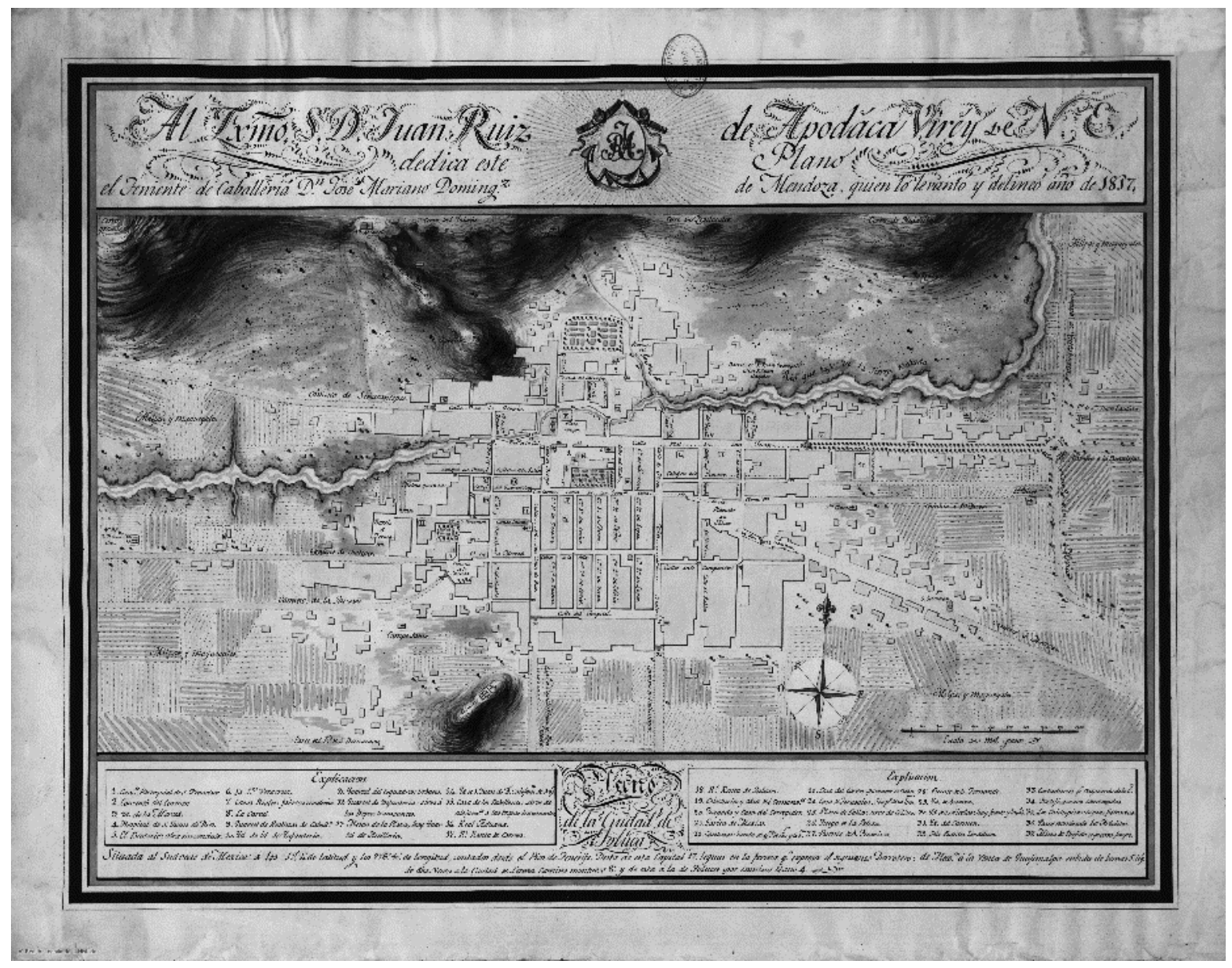

Fig. 6 Plano Original de la Ciudad de Toluca 1817

Fuente: Domínguez de Mendoza (1817)

Con base en el plano que ilustra la Fig. 6, se muestra una traza urbana bien definida adoptando la forma de "tablero de ajedrez" o "damero" con un eje de oriente a poniente y otro que cruzaba perpendicularmente de norte a sur. También se aprecia un sistema regular de cuadrícula, con ángulos rectos teniendo un centro donde se ubica la Iglesia principal y los edificios públicos más importantes. El único río se ubicaba al norte de la ciudad de poniente a oriente cerca del Convento del Carmen, el crecimiento de la ciudad se da a partir del Convento Franciscano y con una tendencia de expansión hacia el oriente de la ciudad.

En cuanto a la propiedad conventual, las órdenes analizadas ocuparon grandes extensiones destacando el Convento Franciscano localizado en el centro de la ciudad así como el Convento del Carmen ubicado en la periferia norte de la ciudad que ocupaba una importante superficie aunque su importancia radica más en el hecho de que esta orden fue la más rica de la ciudad al 


\section{REVISTA DE \\ URBANISMO}

ISSN 0717-5051

http://revistaurbanismo.uchile.cl
Revista de Urbanismo N³1 - Julio - Diciembre de 2014

Departamento de Urbanismo - FAU - Universidad de Chile

contar con mayores bienes construidos que a su vez le significaban un mayor valor a sus propiedades.

En el caso del Convento de la Merced, se identifica que la superficie o extensión de la huerta fue menor a la del Convento Franciscano, además de ubicarse en la periferia poniente de la ciudad, actuando como barrera de la ciudad. En el caso del Hospital de San Juan de Dios, se reconoce que su extensión era la más pequeña a diferencia de los demás conventos. Sin embargo, también tenía un camposanto que abarcaba de un extremo a otro. A continuación se presentan los cambios que sufrió la estructura urbana de la Ciudad de Toluca entre 1817 y 1877 conforme a un análisis cartográfico.

\section{Transformación de la estructura urbana de Toluca 1817-1877}

Con el propósito de identificar los cambios ocurridos de la estructura urbana de la Ciudad de Toluca durante la etapa analizada (1856-1862), se utilizaron los siguientes planos: el trazado por Domínguez de Mendoza en 1817, el de 1854, y de 1877. Estos planos fueron seleccionados considerando el estado original de los polígonos de los cuatro conventos, antes de la desamortización y posterior a la desamortización. Planos que por su gran legibilidad y confiabilidad fueron seleccionados, para después ser digitalizados. Se muestra la comparación de los planos de 1817 con el de 1854, el plano de 1854 con el de 1877, planos en los que se identificó la apertura de calles, lineamientos y su ampliación, así como plazas nuevas.

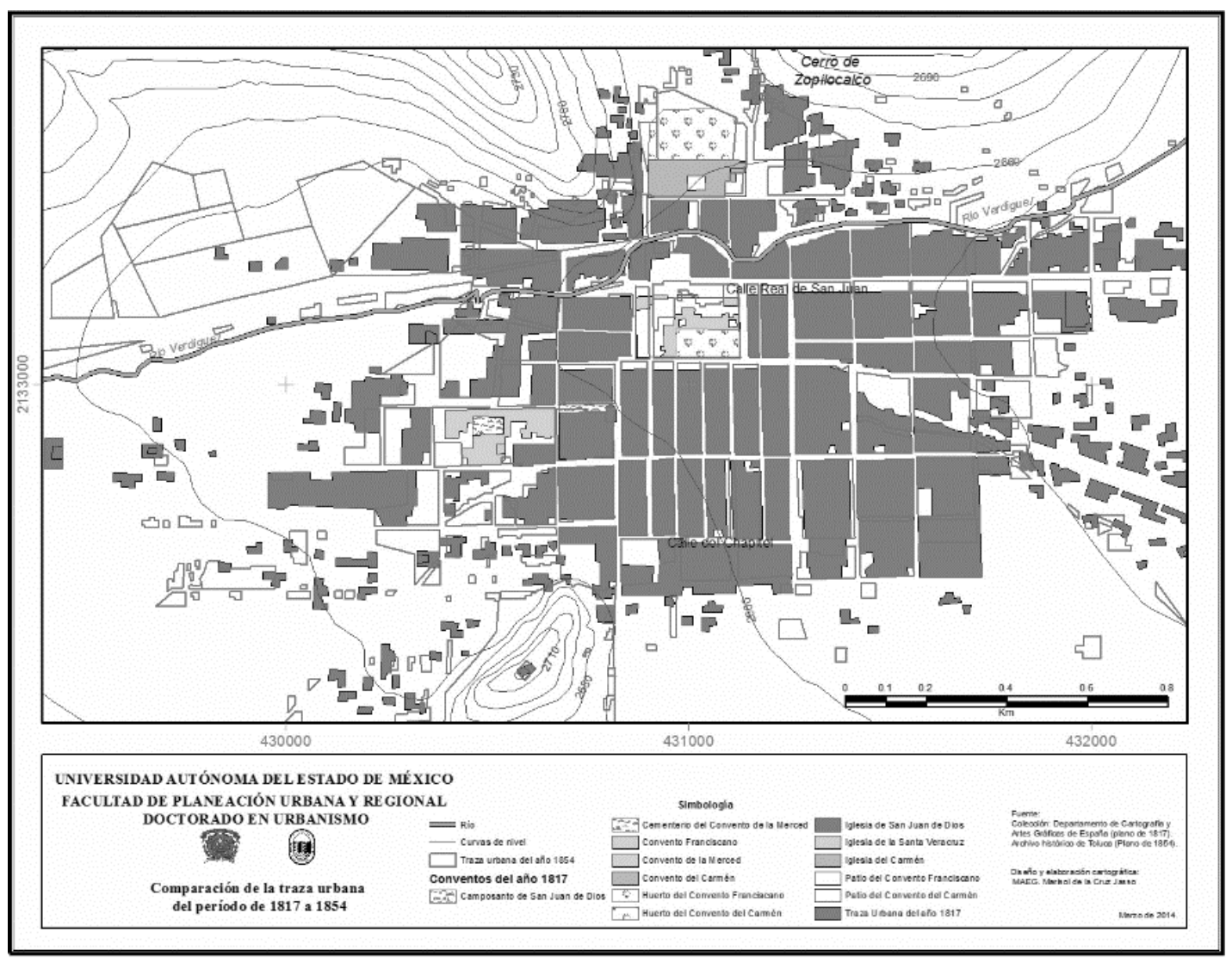

Fig. 7 Traslape de la Traza Urbana de la Ciudad de Toluca 1817-1854

Fuente: Elaboración propia con base en Domínguez de Mendoza, (1817) y Ruíz, (1993) 
Es importante resaltar que se realizaron las comparaciones de cada uno de los planos para identificar los cambios ocurridos antes y después de la desarmortización, a través de la cartografía de cada uno de los planos y, posteriormente, se realizaron las sobre posiciones de años diferentes para que, finalmente, se analizara en distintas perspectivas las transformaciones ocurridas en la ciudad de Toluca y así reconocer si efectivamente la desamortización de bienes eclesiásticos fue una ley que influyó en la configuración urbana de la ciudad. A continuación se presenta el primer plano comparativo de dos años distintos 1817-1854 (Fig. 7).

Entre 1817 y 1854, se distingue la apertura, alineación y ampliación de la calle Morelos, así como la apertura de la calle de Nicolás Bravo, junto con la alineación de la calle de Miguel Hidalgo hacia a un costado de la Plaza del Alva hoy jardín Zaragoza. Además, se realiza la apertura de la calle actual Plutarco González ubicada a un costado del Hospital de San Juan de Dios, el cual antes era parte del campo Santo de los Juaninos. En lo que respecta a los lotes en 1854, se observa mayor división e incorporación de nuevas divisiones, sobretodo en la periferia de la ciudad, aun cuando, no fueron significativas en ese momento para la expansión de la ciudad.

En este periodo se presentó una división del Convento Franciscano en su periferia, así como una división en la huerta del Convento del Carmen y, de manera significativa, una disminución en el Convento de San Juan de Dios, dando la apertura de una calle en lo que era el camposanto del convento (hoy Calle Plutarco González). Es importante destacar que el periodo descrito, la ciudad de Toluca se convirtió en Capital del Estado y que aún no se habían desarrollado las leyes de desamortización. Por lo tanto, los primeros cambios de estos tres conventos religiosos comenzaron desde antes de la desamortización, siendo una etapa importante en la nueva configuración urbana de Toluca, por lo que los cambios en la estructura de la ciudad se dieron desde antes de que se efectuara la desamortización de bienes eclesiásticos entre 1856 a 1862.

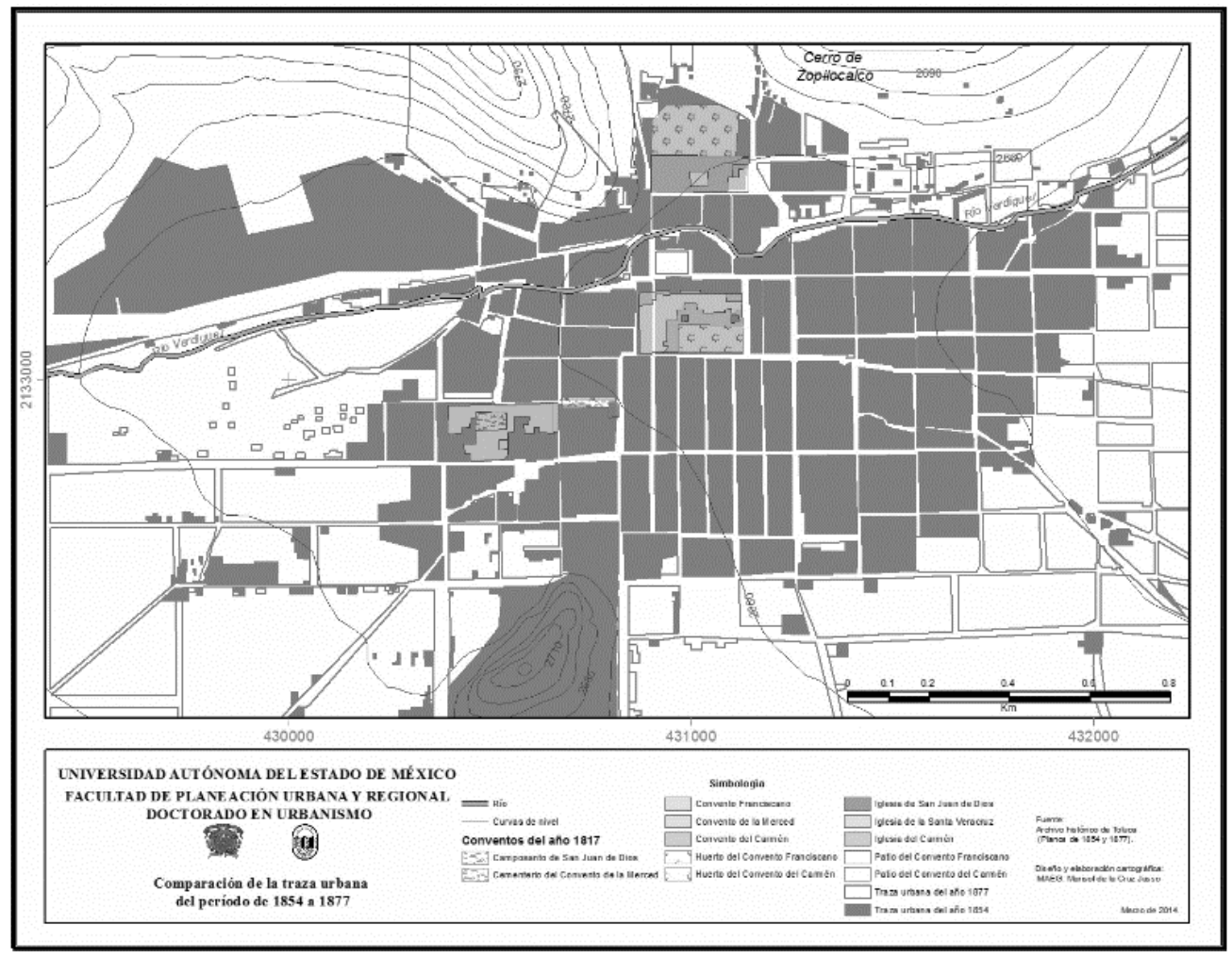

Fig. 8 Traslape de la Traza Urbana de la Ciudad de Toluca 1854-1877 Fuente: Elaboración propia con base en Ruíz, (1993) y Solalinde, (1877) 
En lo que respecta a la propiedad del Convento de la Merced, ésta permaneció en su estado original al menos hasta 1854; tal vez la modificación más importante fue el alineamiento de la Calle de la Merced hoy Calle Morelos favoreciendo la comunicación de la ciudad en sentido oriente-poniente lo que sin duda, favorecería el crecimiento de la ciudad años más tarde, ver Fig. 8.

Con el traslape del plano de la Ciudad de Toluca de los años 1854-1877, se obtuvieron los siguientes cambios: primero, justo donde se ubicaba el Convento Franciscano resalta la apertura de la Calle de la Concordia durante la desamortización de bienes eclesiásticos y que en la actualidad es parte de la Plaza Fray Andrés de Castro y el Pasaje de la Concha acústica. Segundo, también se dio la apertura de la Calle de Quintana Roo hoy en día espacio en el que se ubican asentamientos humanos. Tercero, se definen las calles que conectan con otras localidades siendo el caso del camino a Capultitlán hoy Calle Villada y Paseo Colón y el Camino a México, y el Camino a Coatepec actual avenida Morelos. Por otra parte la Plaza del Alva hoy Jardín Zaragoza sufrió una disminución importante en su superficie siendo sustituida por lotes. También es importante destacar que el tamaño de las manzanas fueron más amplias en 1854.

En lo que respecta al crecimiento de la ciudad en la traza de 1877 , se detecta el surgimiento de colonias nuevas en la zona oriente de la ciudad, siendo el caso del Barrio de San Sebastián, Barrio de Santa Clara, Barrio de Huichila. En la zona suroeste se adicionan más asentamientos, mientras que la zona norte de la ciudad comenzó a darse un crecimiento en el Cerro de Zopilocalco a un costado del Convento del Carmen, proceso que se dio después de la desamortización de bienes eclesiásticos.

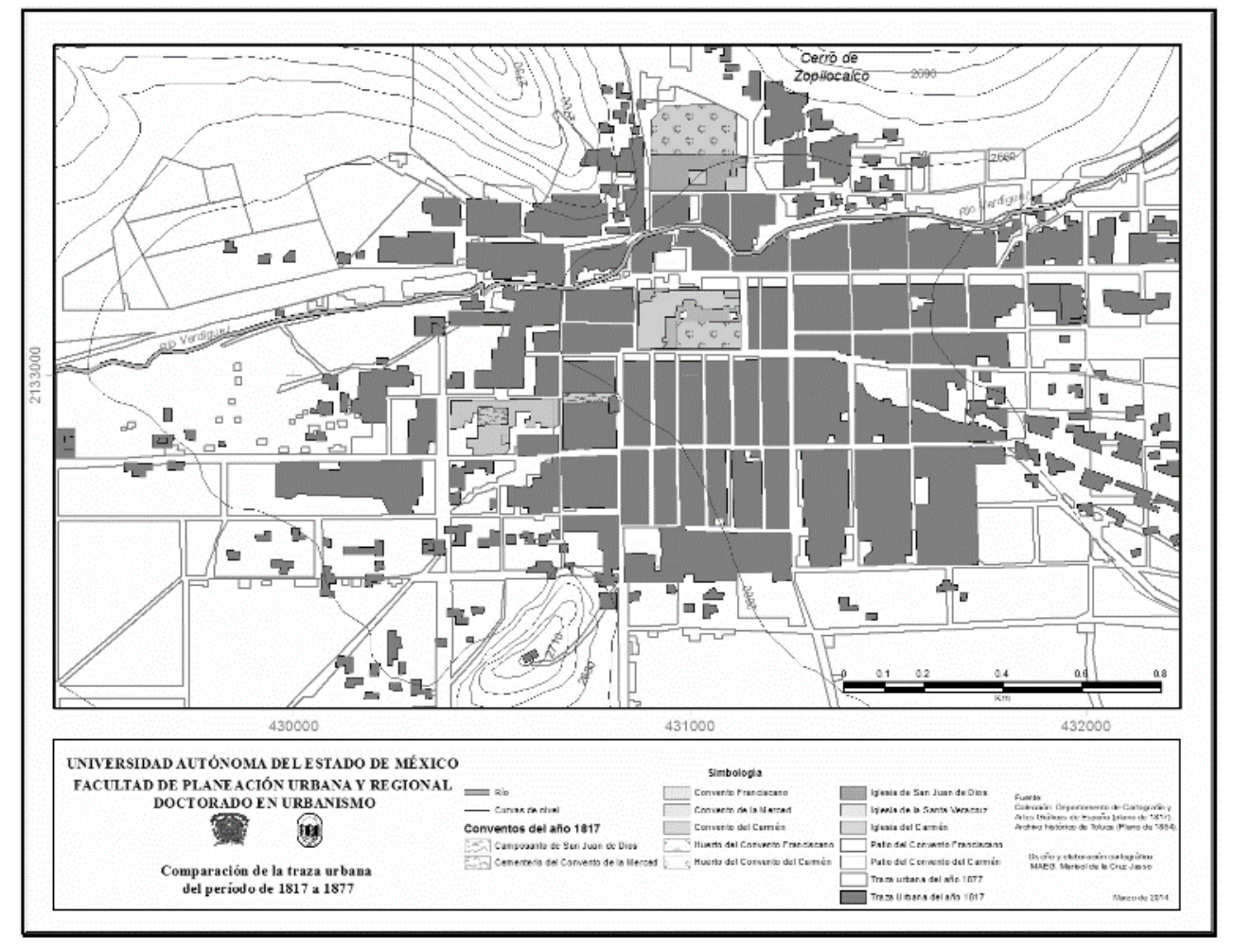

Fig. 9 Traslape de los Planos de la Ciudad de Toluca 1817 y 1877

Fuente: Elaboración propia con base en Domínguez de Mendoza, (1817) y Solalinde, (1877) 
En ese sentido, la expansión de la ciudad de Toluca comenzó a darse a partir de 1877, favorecida sin duda por la ampliación de la calle de la Merced, actualmente calle Morelos lo que originó expansión paulatina de la ciudad hacia la zona poniente. También se reconoce un crecimiento importante en la parte norte de la Ciudad de Toluca, muy cerca del Convento del Carmen, así como en la parte este y sur de la ciudad, mostrando en estos tres puntos un incremento en la cantidad de manzanas. De esta forma, se genera una expansión en la mancha urbana de manera significativa, así como una disminución en los terrenos de cultivo y, por ende, una baja en las actividades primarias por parte de la población, siendo un factor importante para el crecimiento y desarrollo urbano de la ciudad.

En 1877 las propiedades de los cuatro conventos muestran una disminución significativa, permaneciendo solo el atrio principal, los cuales en 1899, pasaron a ser Iglesias. Los terrenos de cultivo que existían en 1877 en la zona sur de Toluca dejaron de existir en su mayoría para convertirse en área urbana. También se observa que se dió un crecimiento importante de asentamienos en el norte de la ciudad en los Cerros del Coporito, Zoopilocalco y Huichuila. Cabe destacar que se mantuvo el Río de Tenería hoy Río Verdiguel completamente cubierto.

Finalmente, se realiza un traslape del plano inicial de 1817 con el de 1877 , con el propósito de identificar las transformaciones ocurridas al inicio de la comparación hasta el final a menera de conclusión final, ver Fig. 9.

Retomando el plano de 1817 y el de 1877, antes y despúes de la desamortización de bienes eclesiásticos se identificaron los siguientes cambios al interior la Ciudad de Toluca entre 1817 a 1877:

\section{Calles abiertas y que aún permanecen en Toluca}

En lo que se refiere a la apertura y alineación de las calles en Toluca, ocurridas antes y después de la desamortización eclesiástica y con base en el anterior plano, se reconoce la apertura de calles importantes que propiciaron el crecimiento de la ciudad favoreciendo la comunicación entre un barrio y otro. Al respecto, destacan la Calle de Nicolás Bravo, la de Plutarco González y la de Melchor Ocampo; asimismo, se observa la alineación y ampliación de la calle de Tenería, actualmente Calle Lerdo, la Calle de la Merced hoy Calle Morelos, ampliación de la Calle San Juan de Dios, después Calle de la Ley y hoy Calle Vicente Villada y la ampliación de Calle de Santa Clara actualmente Calle Hidalgo.

\section{Andadores públicos}

Otro de los cambios que propició la desamortización, fue la incorporación de andadores en el centro de la ciudad, mismos que existen en la actualidad conservando su función original, tal es el caso del andador Concha Acústica (antes Calle de Concordia) así como el andador Constitución antes calle del Maíz y el espacio que ocupan actualmente los Portales, sitio emblemático de la ciudad cuyo emplazamiento coincide con el entonces perímetro oriente del Convento Franciscano.

Plazas y parques públicos

En lo que se refiere a las plazas públicas, y en lo que antes eran los conventos religiosos de Toluca, sólo se da la Plaza González Arratía y la Plaza Fray Andrés de Castro en honor al primer fraile en evangelizar a Toluca. Estas plazas eran propiedades del convento franciscano. En lo que respecta a las demás plazas públicas de la ciudad de Toluca, se dan los siguientes cambios significativos; de acuerdo con el plano de 1817 donde se localizaba la Colecturia y la casa del Comandante fueron, después fueron reemplazadas por uso habitacional y en la actualidad existe la plaza Ángel Ma. Garibay Kintanna. Esta situación también se repitió en el caso de la propiedad privada de la Sra. Micaela quien donó su propiedad para convertirla en lo que hoy conocemos como la Alameda de Toluca. También se han dado reducciones de las plazas que existían en el 
plano de 1817 siendo el caso de la Plaza de la Merced actual Plaza de los Hombres Ilustres y una disminución de la Plaza del Alva actualmente Jardín Zaragoza. Cabe destacar que los últimos cambios se efectuaron después de la desamortización de bienes eclesiásticos.

\section{Crecimiento urbano de la ciudad de Toluca}

Como ya se ha mencionado con anterioridad, se observó un crecimiento impresionante de la ciudad en 1877, generándose nuevos asentamientos humanos en la zona sur en los Cerros de Huichila, Zopilocalco, el Coporito, el Cerro de San Miguel y el Cerro del Toloche y el Barrio de San Juan Evangelista, considerando que en 1817 era cerros cubiertos de árboles y vegetación. También se dió un crecimiento en la zona oriente de la ciudad, cubriendo de asentamientos los barrios de Santa Clara, San Diego, San Juan Bautista y el Barrio de San Sebastián, con dirección hacia el Camino Rea. Cabe destacar que en 1817 eran zonas de cultivo. En la zona sur de la ciudad también se dio un crecimiento de la mancha urbana en los caminos que conducían hacia Calimaya y Capultitlán, así como en camposanto de la Merced estaba ocupado por asentamientos al igual que la zona poniente en el Camino de Coatepec (hoy Calle Morelos) y el Camino de la Garcesa y el Camino a Zinacantepec en la zona sur poniente de la ciudad.

\section{Conclusiones}

La estructura urbana de la ciudad de Toluca durante el siglo XIX, sufrió cambios importantes antes, durante y al finalizar la desamortización de los bienes eclesiásticos. Al respecto, en 1830, la Ciudad de Toluca presentó transformaciones en su configuración urbana a partir de que fue promulgada como capital del Estado, ocasionando la llegada de inmigrantes procedentes de la ciudad de México y del resto del país. Con este proceso, se procuró modernizar a la ciudad para convertirla en burguesa con el mejoramiento en las calles del primer cuadro de la ciudad, y por otra parte, a través de la desamortización de los bienes del clero, se presentó una reducción importante de las propiedades conventuales, ocasionando el aumento de la densidad así como la apertura de calles y nuevos equipamientos urbanos.

Además de darse cambios importantes en las propiedades conventuales, también se presentó la transformación en el resto de la ciudad, considerando que en 1877 se presentó un importante crecimiento de la mancha urbana con el aumento de asentamientos humanos en los barrios de la periferia ocasionando continuidad en las calles que conectaban hacia los poblados colindantes de la ciudad. A pesar de este crecimiento producido por el incremento de la población, la fisionomía de la traza urbana del centro no se modificó y más aún, se continuó en base a las calles que ya existían.

En este contexto, podemos enfatizar que fueron varias las causas que transformaron la estructura de la ciudad. No sólo fue la desamortización, sino que también fue antes de darse dicho periodo, cuando fue promulgada como capital. Por lo tanto se reconoce que a lo largo de la historia, muchos pueden ser los factores que inciden en la configuración de las ciudades y que valen la pena ser identificados para comprender la realidad presentan las ciudades actuales.

\section{Bibliografía}

Barrios, Rozua Juan Manuel. Las desamortizaciones y el Patrimonio Histórico de Andalucía. Edit. Colección Cuadernos del Museo, edad contemporánea. Granada, España. (2009)

Bassols, Coma M. Génesis y evolución del derecho urbanístico español (1812-1956) Madrid, España (1973)

Bazant, Jan. Los Bienes de la Iglesia en México 1856-1875 Segunda Edición. Edit. Colegio de México. México D.F. (1977) 
BAZANT, Mílada. La Desamortización de los Bienes de la Iglesia en Toluca durante la Reforma Edit. Biblioteca Enciclopédica del Estado de México. Toluca, México. (1979)

BAZANT, Mílada. La Desamortización Edit. Clío, Libros y Videos S.A.de C.V. México, D.F. (2011)

DUBLAN y LOZANO, Legislación Mexicana o Colección completa de las disposiciones legislativas. Oficial ed. México (México): s.n (1877).

MARTÍ, Gilabert Francisco. La desamortización española. Edit. RIALP. Madrid, España (2003)

Quiroz, Héctor. Ciudades Mexicanas del Siglo XX Edit. UNAM México, D.F. (2008).

RUEDA, Hernández Germán. Desamortización en España: un balance (1766-1924) Edit. Arco/libros/S. L. Madrid, España (1997).

RUÍZ, Naufal Víctor Manuel. Atlas General del Estado de México Vol. 1 Edit. GEM Gobierno del Estado de México, México (1993).

DOMINGEZ DE MENDOZA, Don José Mariano (1817) Plano de la Ciudad de Toluca situada al Sud-oeste de México á los $19^{\circ} 10^{\prime}$ de latitud y los $276^{\circ} 40^{\prime}$ de longitud,... (1817)" Escala [ca. 1: 8734]. Mil pasos [= 7,9 cm] Biblioteca Virtual del Patrimonio Bibliográfico. Gobierno de España en página electrónica http://bvpb.mcu.es/es/consulta/registro.cmd?id=423437 Fecha de consulta Septiembre 24 del 2011 en Google, España

SOLALINDE (1877), Fotos antiguas de Toluca http://www.mitoluca.com.mx/historia/fotos5.htm. Fecha de Consulta Enero 23 del 2013

CENSO de 1860, A.H.M.T/S.E./C.2/EXP.107/1860/8/6/1, Archivo Histórico del Municipio de Toluca, Sección Especial, Caja 2, Expediente 107 año 1860, expediente que corresponde a las escrituras de capitales que pertenecían al clero.

CENSO de 1865, A.H.M.T./S.E./C.2/EXP.109/1865/8/6/1, Archivo Histórico del Municipio de Toluca, Sección Especial, Caja 2, Expediente 109, año 1865. Inventario de los bienes eclesiásticos. El Alcalde, que en cumplimiento del Art. 32 del Reglamento a la Ley del 26 de Febrero, informa de los capitales eclesiásticos, llevándose acabo inventarios de fincas hipotecadas y demás del municipio de Toluca, habiendo recibido por duplicados las noticias.

CENSO de 1899, A.H.M.T./S.E./C.2/EXP.118/1899/8/6/1 Archivo Histórico del Municipio de Toluca, Sección Especial, Caja 2, Expediente 118, año 1899. Datos estadísticos de los templos, capillas, santuarios y exconventos. El Presidente de la República, a través de la Secretaria de Hacienda y Crédito Público se remitan noticias de los bienes Nacionales y Nacionalizados existentes en el Municipio de Toluca, en particular los relacionados con los templos, capillas, santuarios y exconventos 